\title{
Development, Characterization and Acceptance of Fruit-Bread Biomass Green Brownie
}

\author{
Iris Lengruber de Almeida ${ }^{*}$, Marcia Barreto da Silva Feijó ${ }^{2}$, \\ Paulo Sérgio Marcellini' ${ }^{3}$, Juliana Mérida Pientznauer ${ }^{4}$, \\ Jéssica Borges Oliveira ${ }^{4}$ \\ ${ }^{1}$ Universidade Federal do Estado do Rio de Janeiro (UNIRIO), Niterói, RJ, Brasil \\ ${ }^{2}$ Department of Bromatology of UFF, Universidade Federal Fluminense, Niterói, RJ, Brasil \\ ${ }^{3}$ Department of Biochemistry of UNIRIO-Universidade Federal do Estado do Rio de Janeiro, Rua Frei Caneca, RJ, \\ Brasil \\ ${ }^{4}$ Graduation Courses in Nutrition from the UFF-Universidade Federal Fluminense, Niterói, RJ, Brasil \\ Email: *irislengruber@hotmail.com
}

Received 31 May 2016; accepted 18 July 2016; published 22 July 2016

Copyright (C) 2016 by authors and OALib.

This work is licensed under the Creative Commons Attribution International License (CC BY).

http://creativecommons.org/licenses/by/4.0/

(c) (i) Open Access

\section{Abstract}

Objective: This study aimed to develop and characterize a green breadfruit biomass brownie. Methods: We developed a brownie made with green breadfruit biomass to the detriment of traditional ingredients: flour and butter. We analyzed five replications on the chemical composition (moisture volatile at $105^{\circ} \mathrm{C}$; ashes by calcination; ether extract Soxhlet; protein by the semi-micro Kjeldahl method; starch by Lane-Eynon method) as methodologies recommended by the Adolfo Lutz Institute [1], except the fiber, which was quantified by the method proposed by Van Soest [2]. It was further determined the antioxidant capacity (DPPH) and the content of total phenolic compounds (Folin-Ciocalteu reagent). The brownie was developed subjected to sensory analysis 100 untrained and the result was compared to a traditional version and two trademarks brownie gluten and lactose. Results: On the chemical composition, fiber is an important fraction in developed brownie (12.07 \pm 0.29$)$. For antioxidant capacity, Brownie showed excellent results (DPPH: 85\% and $654.76 \pm 4.10 \mathrm{mg} / 100 \mathrm{~g}$ of gallic acid equivalent) greater than some fruits studied by other authors. The product was developed sensory well accepted, with higher acceptance rate to $70 \%$ in the overall assessment. Conclusion: It was concluded that there viability in production brownie green breadfruit biomass since proved to nutritional appeal even higher than others, with which it was compared, and was well accepted sensorially. One formulation optimization study might be interesting to improve Brownie texture.

${ }^{*}$ Corresponding author.

How to cite this paper: de Almeida, I.L., da Silva Feijó, M.B., Marcellini, P.S., Pientznauer, J.M. and Oliveira, J.B. (2016) Development, Characterization and Acceptance of Fruit-Bread Biomass Green Brownie. Open Access Library Journal, 3: e2778. http://dx.doi.org/10.4236/oalib.1102778 


\title{
Keywords
}

\section{Breadfruit, Biomass, Antioxidants, Fibers, Functional Food, Brownie}

\author{
Subject Areas: Food Science \& Technology
}

\section{Introduction}

Among the many foods considered functional are the fruits, and great attention should be paid to the tropical fruits grown in Brazil, which has extremely favorable conditions on the adaptation of these species. Thus, the consumption of tropical fruits has increased year after year because of the nutritional value and its therapeutic effects, although there is a wide range of derivatives fruits and products still little studied in relation to their properties and ability beneficial to health, as well as their use of variables.

Nutritionally, breadfruit is rich in carbohydrates and a good source of dietary fiber, calcium, copper, iron, magnesium, potassium, thiamine, besides being a good source of antioxidants. However, it is still an underutilized fruit in our country.

In times of valuation issues such as functional food, full use of the food, waste utilization, and several alternatives with nutritious appeal and inexpensive to people's power, it is contradictory so much waste of breadfruit in Brazilian yards.

Because the nutritional value, low cost and ease of access to this fruit, were objectified to develop products that use it as raw material. In this context, it was considered interesting the development of a Green Breadfruit Biomass, which was used in formulating a brownie, replacing ingredients traditionally used, such as butter and flour, thus meeting the call of lactose intolerant and celiac patients at a much more affordable price than those currently offered in the market, and presented the functional appeal for having shown rich in fiber and antioxidants.

\section{Methods}

The Brownie was produced through an original recipe [1], which was made the substitution of ingredients butter and flour for Green Breadfruit Biomass. The brownie was baked in a preheated oven at $180^{\circ} \mathrm{C}$ for 15 minutes in an aluminum shape without smearing. After baked, the brownies were manually crumbled and a portion was removed for moisture analysis and the rest was spread on an aluminum pan evenly and taken to the oven at $105^{\circ} \mathrm{C}$ to dehydrate. After dehydrated, it was crushed in a domestic blender until it became a homogeneous powder and then stored in glass with a lid.

\subsection{Centesimal Composition}

The analyzes were done in five replications and methodological procedures were performed at the Bromatology Laboratory of the Universidade Federal Fluminense.

The humidity was determined gravimetrically, at $105^{\circ} \mathrm{C}$ until constant weight according to the method recommended by Adolfo Lutz Institute [2], as well as fixed mineral residue in oven at $550^{\circ} \mathrm{C}$ to constant weight.

The ether extract fraction was determined by Soxhlet extractor intermittently, using ether as solvent Ethyl PA [2].

Protein was determined by the Kjeldahl method (semi-micro), which is based on the destruction of organic matter followed by distillation and nitrogen dosed by volumetry. The factor of 6.25 was used to convert the total nitrogen content of protein according to the conversion factors used by FAO/73 [2].

The carbohydrate was determined in starch, the Lane-Eynon method, which is based on the ability of glícides in strongly alkaline and hot medium to form enodiol, compound having strong reducing power, which in the presence of $\mathrm{Cu}^{++}$, oxidizes and reduces copper $\mathrm{Cu}^{+}$, to give a brick red precipitate $\mathrm{Cu}_{2} \mathrm{O}$ [3].

The fiber was determined by the method proposed by Van Soest, 1963 [3], using a neutral detergent solution (NDF), which solubilizes all plant material, except for the wall structure that are insoluble fiber (cellulose, hemicellulose and lignin). After the filtrate is vacuum residue NDF, which is subsequently washed with boiling 
distilled water, followed by washing with acetone PA for better drying.

This method quantifies the insoluble fraction of fiber (cellulose, hemicellulose and lignin).

\subsection{Antioxidant Capacity}

The extracts were analyzed in triplicate, in Bioactive Laboratory of the State Federal University of Rio de Janeiro (UNIRIO).

For the extracts, were weighed 10 grams desiccated in a sample tube and added $10 \mathrm{ml}$ water (to aqueous extract) and another tube with $10 \mathrm{ml}$ of ethanol (for the alcoholic extract). After one hour the tubes were centrifuged for 10 minutes at 20,000 revolutions per minute with acceleration and deceleration of twenty seconds 30 seconds [4].

Each sample solution was subjected to the determination of the ability to scavenge radical 1,1-diphenyl-2picrylhydrazyl (DPPH), according to the method described by Brand-Williams et al. (1995) modified by Miliauskas et al. (2004), and referenced by PRIOR; WU \& Schaich, 2005 [5]. The radical absorbance measured after one hour reaction was carried out at a wavelength of $517 \mathrm{~nm}$. The decline in reading the optical density of the samples was correlated with the control, setting the percentage of discoloration of DPPH radical, according to the formula below:

$$
\% \text { Protection }=(\text { Abs control }- \text { Abs sample }) / \text { Abs control }
$$

The determination of the content of phenolic compounds in the solution was carried out by spectrophotometry in the visible region using the classical method of Folin-Ciocalteu reagent and the absorbance of the samples was measured at $750 \mathrm{~nm}$. The total phenolics content was determined by interpolating the absorbance of the samples against a calibration curve constructed with gallic acid standards (0 to $20 \mathrm{mg} / \mathrm{ml}$ ) and expressed as $\mathrm{mg}$ of GAE (gallic acid equivalents) per 100 grams of sample as referenced by Singleton and Rossi, (1965) with modifications established by Bonoli et al., (2004), and referenced by Melo [4].

\subsection{Sensory Analysis}

Sensory tests were performed in the Sensory Analysis Laboratory of the UFF Nutrition College in suitable environment, air-conditioned and airy, under natural light. They recruited 100 subjects of both sexes, of the University randomly aged between 18 and 58 years.

Before starting the sensory analysis, participants were asked to fill out a consent form and clarified to ensure the voluntary nature of the research. In sequence, completed a nominal scale in order to identify the consumption profile.

Four samples were offered 20 grams each, for each tester, a monadic manner. The samples were coded with three digits, always accompanied by a glass of water at room temperature, and a biscuit salted water to the mouth and tongue cleaning before each assessment. It was then an order of random presentation [6].

Two of the samples were commercial, chosen based on the niche occupied by the formulations, which is the health of appeal, purchased in health food stores, both gluten free. A brand ready for consumption and the other a brownie mix to another brand of gluten, which was prepared according to the manufacturer's guidelines. It has not yet made a brownie in the traditional way and the brownie developed with Green Breadfruit Biomass.

The offered samples were subjected to acceptance affective test, which evaluated the sensory attributes involved: color, aroma, flavor and texture, using a hedonic scale of 9 points whose grades will range from 1 (extremely disliked) to 9 (like extremely). For the acceptance test using affective attitude scale, the ratings are provided "definitely buy" (5) until "certainly would not buy" (1). Using the methodology (165/IV) recommended by the Adolfo Lutz Institute-ITB [1]. The test was carried out with prior permission of the Ethics Committee of the UFF, number 1,024,216 opinion adopted on 10 April 2015. The sample acceptance rate was calculated by the following mathematical expression using the Question of the overall impression of the product [7]:

$$
\mathrm{IA}=\mathrm{X} * 100 \% / \mathrm{N}
$$

At where:

$\mathrm{X}=$ average of each sample.

$\mathrm{N}=$ maximum grade of each sample, given by the panelists. 


\subsection{Statistical Analysis}

The results were evaluated statistically, to obtain mean and standard deviation, and subjected to analysis of variance ( $\mathrm{p}<0.05$ - ANOVA and Tukey’s test to compare means using the ASSISTAT program version 7.7 beta.

\section{Results}

\subsection{Centesimal Composition}

Table 1 shows the results of the chemical composition of the Breadfruit Brownie, compared to the results found in an earlier study for the Green Breadfruit Biomass.

\subsection{Antioxidant Analysis}

The results of DPPH analysis were expressed as a percentage reduction and the EC50 is the sample concentration capable of removing $50 \%$ of the free radical DPPH and were compared with results of previous studies with values for breadfruit in nature and Biomass of Breadfruit Green. As can be seen in Table 2, the aqueous extract of breadfruit showed $85 \%$ reduction of DPPH $\left(0.97 \mathrm{R}_{2} / \mathrm{EC}=0.87\right)$ after a contact time. But the alcoholic extract showed $77 \%\left(\mathrm{R}_{2} 0.90\right)$ reduction. Demonstrating best extraction in the aqueous extract, as also reported by Melo [8] in their study with frozen fruit pulps, which found $89 \%$ of DPPH reduction in aqueous extract to the pulp of soursop and hog plum, and $65 \%$ for pulps passion fruit and pineapple. The aqueous extract of biomass showed $82 \%$ reduction of DPPH $\left(0.98 \mathrm{R}_{2} / \mathrm{EC}=1.18\right)$ and the brownie $85 \%\left(0.91 \mathrm{R}_{2} / \mathrm{EC}=0.70\right)$.

Regarding phenolic compounds, breadfruit presented $615.98 \pm 12.44 \mathrm{mg}$ gallic acid equivalent (per $100 \mathrm{~g}$ of sample), whereas in the biomass were found $451.36 \pm 10.24 \mathrm{mg} / 100 \mathrm{~g}$ and 654 brownie, $76 \pm 4.10 \mathrm{mg} / 100 \mathrm{~g}$, as shown in Table 2. Moura [9] found in the pulp of acerola $835.25 \mathrm{mg} / 100 \mathrm{~g}$ cashew $449.63 \mathrm{mg} / 100 \mathrm{~g}$.

\subsection{Sensory Analysis}

The age profile prevalent among respondents was between 20 and 29 years. As the survey was conducted at the School of Nutrition, women were present in greater amounts than men. Thus, it can be said that most research participants were young adult women.

Table 1. Proximate composition (g/100g): Green breadfruit biomass and brownie green breadfruit biomass.

\begin{tabular}{ccc}
\hline Fraction & Biomass & Brownie \\
\hline Moisture & $87.29 \pm 0.09^{\mathrm{b}}$ & $5.46 \pm 0.62^{\mathrm{c}}$ \\
Ashes & $0.80 \pm 0.01^{\mathrm{b}}$ & $1.02 \pm 0.03^{\mathrm{c}}$ \\
Lipid & $0.39 \pm 0.03^{\mathrm{b}}$ & $2.42 \pm 0.36^{\mathrm{c}}$ \\
Protein & $1.19 \pm 0.13^{\mathrm{b}}$ & $6.27 \pm 0.08^{\mathrm{c}}$ \\
Carbohydrates & $3.86 \pm 0.49^{\mathrm{b}}$ & $10.35 \pm 0.37^{\mathrm{c}}$ \\
Fiber & $12.66 \pm 0.55^{\mathrm{b}}$ & $12.07 \pm 0.29^{\mathrm{c}}$ \\
\hline
\end{tabular}

\begin{tabular}{ccc|}
\hline Table 2. Antioxidant analysis. & & \\
\hline Sample & DPPH $^{*}$ & $\mathrm{GAE}^{*}$ \\
\hline Green breadfruit & $85^{\mathrm{a}}$ & $615.98 \pm 12.44^{\mathrm{a}}$ \\
Green breadfruit biomass & $82^{\mathrm{b}}$ & $451.36 \pm 10.24^{\mathrm{b}}$ \\
Brownie green breadfruit biomass & $85^{\mathrm{a}}$ & $654.76 \pm 4.10^{\mathrm{c}}$ \\
\hline
\end{tabular}

Means followed by the same letter in the same column do not differ statistically to each other (Tukey test-5\% probability); ${ }^{*}$ Results are expressed as percentage of reduction; ${ }^{* *}$ Results are expressed as mg of gallic acid per $100 \mathrm{~g}$ of sample. GAE-“gallic acid equivalents”. 
On the monthly frequency of consumption of brownies or chocolate cakes, it turns out that most people (91\%) who responded to the survey consume this type of product at least once a month.

Table 3 shows the marks awarded by the judges to the four brownie formulations.

Regarding the attribute "aroma", the only sample that differed from others was also formulated with powder for mixing brownie. The comments of the panelists were "oil smell"; "Does not smell of chocolate", among others.

Regarding the taste, the formulation more acceptable was the standard. The formulation with Biomass showed no significant difference from commercial ready. The main observations of the panelists compared to the taste of the Biomass formulation were "less sweet than the others"; "Could be sweeter"; "I thought bitter". This is explained because the standard formulation is with refined sugar and cocoa powder. While the formulation is biomass with raw sugar and cocoa powder. The lack of milk in the formulation also changes the sense of sweet taste. Comments for formulation with dust and the brownie ready brought comments on the "chemistry of taste"; and type "seems ready market cake".

In the texture attribute, it can be seen that the formulation Biomass was not well placed, being preferred by the panelists traditional formulation. Regarding the brownie ready, the comments were "very crumbly"; "Very floury"; "Looks crumbly", among others. As for the formulation Biomass, what else was seen by the panelists was the texture "softened"; "soft"; "Melequenta"; "Too wet", among other expressions. What may not be a big problem. So much so that some tasters who gave a score for texture, rightly pleased with the smooth texture. But compared with brownies, in fact, until it does not contain any flour in their formulation, it appears much more humid.

Regarding the overall impression attribute, the standard formulation was better accepted, followed by formulation with biomass that did not differ from ready. Finally, the powder mix, as can be seen in Table 3.

It has been calculated yet, the IA (acceptance rate) of each attribute.

By observing IA (acceptance rate) of the overall impression, it is concluded that the sample had greater acceptance has been the traditional formulation, followed by the sample from this study, formulated with Green breadfruit biomass, and then the sample soy selling ready for consumption. Finally, the sample corresponding to the powder to soybean brownie mix. The results can be better observed in Figure 1.

According Finger [7] to a good impact the acceptance rate should exceed $70 \%$. Thus, we can say that in relation to the overall impression, just sample "powder mixture" was not well received.

We also analyzed the buying attitude of the tasters with the 5-point scale, which were "certainly would not buy"; "probably would not buy”; "Maybe buy/may not buy"; "Probably buy” and "definitely buy”. The sample that had the best average score was the standard formulation, as expected (Figure 1).

\section{Discussion}

In Table 4, it is a comparison of the results of the chemical composition of the Green Breadfruit Biomass Brownie with a commercial brownie gluten and lactose.

The results demonstrate that breadfruit exhibits excellent antioxidant capability, even higher than some fruits found in the literature. Many studies have shown that phenolic compounds generally decrease in Climacteric fruits such as tomatoes, bananas, mangoes and guavas during ripening [10] which may also have contributed to the high submitted antioxidant capacity, as the present study is the fruit still green. It is observed that the

Table 3. Mean and standard deviation of scores for each attribute obtained panel test.

\begin{tabular}{|c|c|c|c|c|}
\hline Attributes & Standard & Biomass & Ready & Powder mix \\
\hline Appearance & $7.95^{\mathrm{a}} \pm(1.12)$ & $7.62^{\mathrm{a}} \pm(0.92)$ & $6.71^{\mathrm{b}} \pm(1.82)$ & $4.95^{\mathrm{c}} \pm(1.93)$ \\
\hline Aroma & $7.37^{\mathrm{a}} \pm(1.39)$ & $7.36^{\mathrm{a}} \pm(1.06)$ & $7.04^{\mathrm{a}} \pm(1.75)$ & $5.04^{\mathrm{b}} \pm(1.89)$ \\
\hline Flavor & $7.83^{\mathrm{a}} \pm(1.33)$ & $6.93^{\mathrm{b}} \pm(1.31)$ & $6.79^{\mathrm{b}} \pm(1.84)$ & $5.26^{\mathrm{c}} \pm(2.24)$ \\
\hline Texture & $8.05^{\mathrm{a}} \pm(1.31)$ & $5.20^{c} \pm(2.39)$ & $6.51^{\mathrm{b}} \pm(1.84)$ & $5.29^{c} \pm(2.28)$ \\
\hline Global impression & $7.91^{\mathrm{a}} \pm(0.99)$ & $6.82^{\mathrm{b}} \pm(1.24)$ & $6.71^{\mathrm{b}} \pm(1.66)$ & $5.24^{\mathrm{c}} \pm(1.91)$ \\
\hline Buy intention & $4.29^{\mathrm{a}} \pm(0.79)$ & $3.50^{\mathrm{b}} \pm(0.84)$ & $3.30^{\mathrm{b}} \pm(1.14)$ & $2.38^{\mathrm{c}} \pm(1.00)$ \\
\hline
\end{tabular}

Letters equal the same lines represent statistically equal results, and different letters represent significant differences by Tukey test ( $p<0.05)$. 


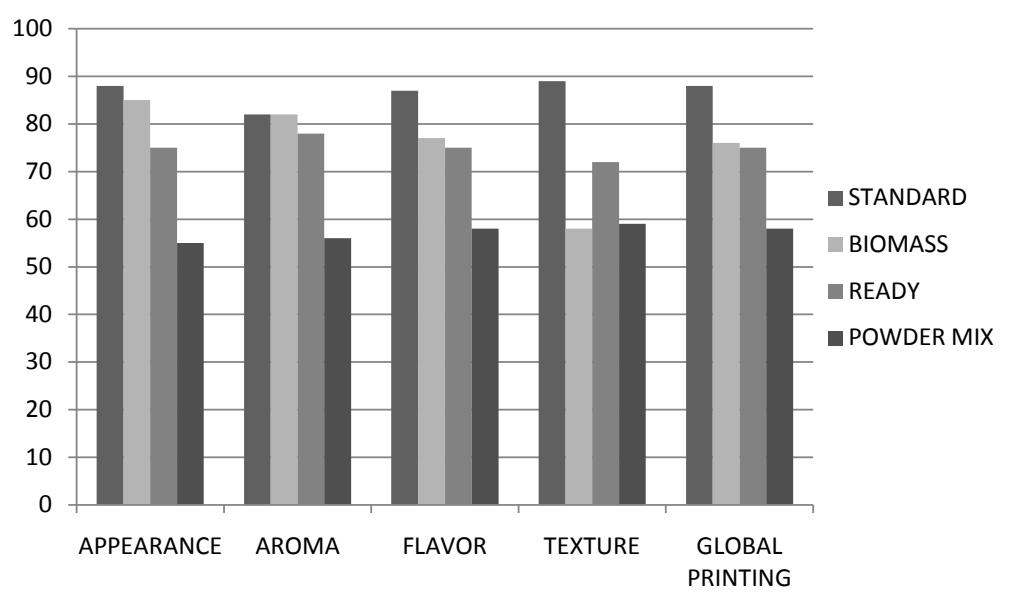

Figure 1. IA (Acceptability Index)\% of attributes.

Table 4. Proximate composition (g/100g): Brownie green breadfruit biomass and commercial gluten-free brownie ready.

\begin{tabular}{ccc}
\hline Fraction & Biomass & Commercial \\
\hline Lipid & 2.4 & 18.1 \\
Protein & 6.3 & 5.3 \\
Carbohydrates & 10.4 & 51.6 \\
Fiber & 12.07 & 1.6 \\
Calorie & 88 & 392 \\
\hline
\end{tabular}

antioxidant capacity decreased but persisted high in developed biomass, suggesting that it can be used with no significant loss of nutritional and functional value.

Interesting to note that the antioxidant capacity grows back in Brownie developed with the Green Breadfruit Biomass. What can be attributed to cocoa added to the recipe, which has recognized antioxidant value, or the fact that Melo [8] studied on the effect of heat treatment on antioxidant capacity in vegetables. In which it quoted that during heat treatment can occur several events which justify the change in antioxidant capacity and can not change, increase or decrease the food antioxidant action. In the situation where there is increased antioxidant in food, heat treatment provides the partial oxidation of bioactive compound that exhibits greater ability to donate hydrogen atom to radical from the hydroxyl group and/or the aromatic structure of the polyphenol is more ability to withstand the unpaired electron of displacement around the ring. Furthermore, the heat treatment may promote the formation of new compounds, such as Maillard reaction products (redutonas), which have antioxidant activity [10]. Interestingly, the Green Breadfruit presented an intermediate value between the fruit already recognized sources of antioxidants such as acerola and cashew.

Regarding the profile of the tasters participating in the Sensory Analysis, as it is a product that covers a wide age range, would be more interesting if there was a balance amount of people in each age group. However, this factor does not compromise the development of the product, according to Borges et al. [11], although it is not a staple food like bread, brownie is accepted and consumed by people of any age.

As the ABIMA (Brazilian Association of Food Industries Pasta and Bread \& Cakes Industrialized), due to increased purchasing power and the rise of classes $\mathrm{D}$ and $\mathrm{E}$, the Brazilian is with sophisticated palate. One of the sectors that may well reflect this change in consumer behavior is the cake ready. According to a study by Kantar World panel [12] the category was present in $41 \%$ of Brazilian households in 2011, but rose to $45 \%$ in 2012, which means that more than 2 million families are now eating cake ready in one year. This was the sector with the highest growth among the wheat derivative analyzed by the consulting firm. This explains the frequency with which the tasters consume brownie or chocolate cake.

As can be seen in Table 3, the attribute "appearance”, the Biomass Brownie showed no significant difference 
from the standard formulation. Both got good grades. Ready Brownie did not score as well but was above average, while the powder mixture was below average. The comments of the panelists for the latter were "not seem brownie"; "Ugly color", among others.

The sample formulated with Biomass showed no significant difference for the early commercial sample (Table 3). This is a good result, since the commercial brownie ready is a strong brand in the market, which sells products without gluten and lactose. And although the formulation Biomass has an infinitely greater functional appeal, because it is a formulation without milk, without any kind of meal without any fat and organic demerara sugar. The ready market brand has a wide range of processed ingredients: sugar; gluten mix (brown rice flour, corn starch, cassava starch, whole soy flour); vegetable oil; cashew nut; eggs; cocoa powder; as well as preservatives and flavorings. Not to mention that the brownie green Breadfruit Biomass also has antioxidant naturally found in fruits.

\section{Conclusion}

This study found that even with the processing and submission to the high temperature for the production of biomass and subsequent production of brownie breadfruit green biomass, no significant loss of nutrients observed. This research denoted that there was viability for production and marketing of Brownies, due to the low cost of its ingredients, preparation of simplicity and maintenance of functional properties. The measured sensory acceptance was satisfactory, since the Acceptability Index (AI) to the overall impression was greater than $70 \%$. As breadfruit is more abundant precisely in disadvantaged regions economically, and its consumption is still not widespread, it is concluded that the incentive to use this fruit in other national territories, would bring greater income for small farmers and increased utilization of production annual, decreasing wastage of fruit and thereby contributing to public health, since it is a product with functional appeal, and the country's economy through new income generation.

\section{References}

[1] Petitgastrô (2012) História do Brownie. http://www.petitgastro.com.br/2012/01/historia-do-brownie/

[2] São Paulo (2008) Normas analíticas do Instituto Adolfo Lutz. Métodos físicos e químicos para análise de alimentos, São Paulo, n. 4.

[3] Van Soest, P.J. (1963) The Use of Detergents in the Analysis of Fibrous Feeds: II. A Rapid Method for the Determination of Fiber and Lignin. Official Agriculture Chemistry, 46, 829.

[4] Melo, E.A. (2006) Capacidade Antioxidante de Hortaliças Usualmente Consumidas. Ciência e Tecnologia de Alimentos, Campinas, 26, 639-644. http://dx.doi.org/10.1590/S0101-20612006000300024

[5] Prior, R.L., Wu, X. and Schaich, K. (2005) Standardized Methods for the Determination of Antioxidant Capacity and Phenolics in Foods and Dietary Supplements. Journal of Agricultural and Food Chemistry, 53, 4290-4302. http://dx.doi.org/10.1021/jf0502698

[6] Martínez-Cervera, S. (2012) Rheological, Textural and Sensorial Properties of Low-Sucrose Muffins Reformulated with Sucralose/Polydextrose. LWT Food Science and Technology, Valencia, 45, 213-220. http://dx.doi.org/10.1016/j.lwt.2011.08.001

[7] Finger, C.L., Scheidt, D.T. and Deina, L.E. (2010) Desenvolvimento e análise sensorial de petit suisse de maracujá e mexerica. Anais do II Encontro de Divulgação Científica e Tecnológica. Universidade Tecnológica Federal do Paraná, Paraná.

[8] Melo, E.A. (2008) Total Phenolic Contents and Antioxidant Capacity of the Frozen Fruit Pulps. Alimentos e Nutrição, Araraquara, 19, 67-72.

[9] Moura, S.M. (2010) Estabilidade da Acerola em Pó Oriunda de Cultivo Orgânico. Universidade Federal do Paraná (Dissertação de Mestrado), Fortaleza, 112f.

[10] Nicoli, M.C., Anese, M. and Parpinel, M. (1999) Influence of Processing on the Antioxidant Properties of Fruits and Vegetables. Food Science \& Technology, 10, 94-100. http://dx.doi.org/10.1016/S0924-2244(99)00023-0

[11] Borges, J.T.D.S. (2006) Utilização de farinha mista de aveia e trigo na elaboração de bolos. Boletim Ceppa, 14, 145162. http://dx.doi.org/10.5380/cep.v24i1.5286

[12] (ABIMA) Associação brasileira das indústrias de massas alimentícias e pãos \& bolos industrializados. ABIMA. www.abima.com.br http://www.abima.com.br/noticias_eabima.php?id=765 